\title{
Temperature dependent electrical conductivities of fruit purees during ohmic heating
}

\begin{abstract}
Ohmic heating takes its name from Ohm's law; the food material switched between electrodes has a role of resistance in the circuit. In this study, the apricot and peach purees were heated on a laboratory scale static ohmic heater by applying voltage gradients in the range of 20-70 $\mathrm{V} / \mathrm{cm}$. The voltage gradient was statistically significant on the ohmic heating rates for both purees $(\mathrm{P}<0.05)$. The linear temperature dependent electrical conductivity relations were obtained. Bubbling was observed above $60^{\circ} \mathrm{C}$ especially at high voltage gradients. The ohmic heating system performance coefficients were in the range of 0.49-1.00. The unsteady-state heat conduction equation for negligible internal resistance was solved with an ohmic heating generation term by the finite difference technique. The predictions of the mathematical model using obtained electrical conductivity equations were found to be very accurate. (C) 2005 Elsevier Ltd. All rights reserved.
\end{abstract}

Keyword: Electrical conductivity; Fruit purees; Modelling; Ohmic heating 